\title{
An Estradiol-Induced Protein Synthesized in the Ventral Medial Hypothalamus and Transported to the Midbrain Central Gray
}

\author{
Charles V. Mobbs, Richard E. Harlana, Mary R. Burrous, and Donald W. Pfaff \\ The Rockefeller University, New York, New York 10021
}

Estradiol $\left(E_{2}\right)$ facilitates the lordosis reflex that occurs in response to flank stimulation in female rats. Lordosis appears to be regulated in part by the synthesis of proteins in the ventral medial hypothalamus (VMH) that are transported to the midbrain central gray (MCG). We developed a strategy involving microinfusion of radioactive amino acids, followed by 2-dimensional gel electrophoresis, to identify proteins that may be regulated by $E_{2}$ in the VMH and transported to the MCG. A mixture of ${ }^{35} \mathrm{~S}-$ methionine and ${ }^{35}$ S-cysteine (2:1, total 500-1000 $\mu \mathrm{Ci}$ ), suspended in $1 \mu$ l PBS, was infused bilaterally into the VMH over a period of $2 \mathrm{hr}$ into matched pairs of ovariectomized female rats, one of which was given a Silastic implant containing $E_{2}$ at the beginning of infusion or 1 week earlier. The rats were sacrificed $12 \mathrm{hr}$ after the end of infusion, and several brain regions were obtained by microdissection. Samples were analyzed by 2-dimensional gel electrophoresis, entailing isoelectric focusing in the first dimension and SDS-PAGE (molecular-weight separation) in the second dimension, followed by fluorography. We could routinely separate at least 250 spots. We consistently found a protein spot with an apparent molecular weight of $70 \mathrm{kDa}$, pl of about 5.9, which almost always appeared in the VMH and MCG of rats given $E_{2}$ replacement but very rarely in samples from ovariectomized rats given no $E_{2}$ replacement. A spot immediately acidic to this protein $(70 \mathrm{kDa}$, pl about 5.8) appeared to vary inversely with this $E_{2}$-induced protein. Three lines of evidence suggest that the labeled protein in the MCG was due primarily to transport from the VMH: (1) Radloactivity after infusion was much higher in regions with hypothalamic projections than in other regions, and in the MCG tended to be found over axonal tracts rather than cell bodies; (2) colchicine reduced the radioactivity in the MCG by about $90 \%$; and (3) despite variation between individuals, the relative densities of the $70 \mathrm{kDa}$ proteins were identical in the VMH and MCG in the same individual. It is not clear if the $70 \mathrm{kDa}, 5.9 \mathrm{pl}$ protein was synthesized de novo in response to $E_{2}$ or was the result of a modification of the $\mathbf{5 . 8}$

Received Nov. 7, 1986; revised June 15, 1987; accepted June 24, 1987.

This work was supported by NIH Grants AG05326 to C.V.M., NS19985 to R.E.H., and HD05751 to D.W.P.

We also appreciate the excellent technical assistance of Mark Kalamarides, and helpful discussions with Drs. Susan Fox, Kathryn Jones, Brenda Shivers, and Bruce McEwen. R.E.H, was a recipient of the Irma T. Hirschl Career Scientist Award.

Correspondence should be addressed to Charles V. Mobbs, The Rockefeller University, 1230 York Ave., New York, NY 10021.

Present address: Department of Anatomy, Tulane University Medical Center, New Orleans, LA 70112.

Copyright $(C) 1988$ Society for Neuroscience $0270-6474 / 88 / 010113-06 \$ 02.00 / 0$ pl protein. In any case, these studies suggest that $E_{2}$ causes the appearance of this protein in the VMH, from whence it is transported to the MCG. The function of this protein remains unknown; however, the molecular weight and isoelectric point of this protein are similar to those of an isoform of the proteins that remove clathrin from coated secretory vesicles, themselves part of the family of stress-induced proteins.

In the presence of picomolar levels of circulating estradiol $\left(E_{2}\right)$, female rats will exhibit the rigid reflexive posture, lordosis, when pressure is exerted on flank and perineal skin areas. In the absence of $\mathrm{E}_{2}$, this reflexive response is almost completely absent (Pfaff, 1980). In non-neural cells, $E_{2}$ alters transcription and induces synthesis of specific proteins (O'Malley and Means, 1974). Previous work has shown (1) that $E_{2}$ can facilitate lordosis by acting through receptors in the ventral medial hypothalamus (VMH) (Pfaff, 1980); (2) that blocking protein synthesis (Meisel and Pfaff, 1985) or axonal transport (Harlan et al., 1982) in the VMH will block lordosis; and (3) that destruction of neuronal fields in the midbrain central gray (MCG) region will block lordosis (Sakuma and Pfaff, 1979). These and other data suggest that $E_{2}$ facilitates lordosis in part by inducing the synthesis of specific proteins or peptides, some of which are transported to the MCG, where they may regulate the functional connections between flank somatosensory afferents and motoneurons controlling back muscle contraction. The identification of such proteins could provide potential tools for investigating biochemical mechanisms related to synaptic facilitation. In this study we report the detection, using intrahypothalamic infusion of radiolabeled amino acids followed by 2 -dimensional gel clectrophoresis, of a protein synthesized in the $\mathrm{VMH}$, induced by $E_{2}$, and apparently transported to the MCG.

\section{Materials and Methods}

Animals. Female Sprague-Dawley-derived rats (Charles River) were maintained in a $12 \mathrm{~L}: 12 \mathrm{D}$ photoperiod. The rats were $3-4$ months old, weighed 220-260 gm, and were ovariectomized under Metofane (methoxyflurane; Pitman-Moore) 4-7 d before further treatment. $E_{2}$ capsules consisted of Silastic tubing (Dow Corning, $2.96 \mathrm{~mm}$ o.d., $1.47 \mathrm{~mm}$ i.d., $5 \mathrm{~mm}$ releasing length) filled with crystalline $\mathrm{E}_{2}$. The results in this paper represent data from 16 pairs $\left(E_{2}\right.$-treated vs non- $E_{2}$-treated) of rats, from 3 separate cohorts, studied over a period of 6 months. The first 2 pairs of rats were given implants 1 week before infusion of radioactive amino acids, and the rats bearing $E_{2}$ implants exhibited lordosis behavior just before sacrifice; the second 2 pairs were given $E_{2}$ implants $14 \mathrm{hr}$ before sacrifice. One of each of these pairs was infused with ${ }^{35} \mathrm{~S}$-methionine, and the other 2 pairs were infused with ${ }^{35}$ S-cysteine. The next 12 pairs of rats were infused with a combination of the 2 radiolabels (see next paragraph). Four of these pairs were sacrificed 1 week, and the other 8 
pairs were sacrificed $14 \mathrm{hr}$, after initial exposure to $\mathrm{E}_{2}$ (see below). Gels from VMH samples of all these pairs are included in the results from this study, although gels from MCG samples derive only from the first 2 and last 8 pairs.

Stereotaxic surgery and infusions. Tissue from $\mathrm{E}_{2}$ - and sham-implanted controls was labeled and processed in matched pairs. ${ }^{35} \mathrm{~S}-\mathrm{methionine}$ $(600 \mu \mathrm{Ci})$ and ${ }^{35} \mathrm{~S}$-cysteine $(300 \mu \mathrm{Ci})$ (New England Nuclear; $800 \mathrm{Ci}$ / $\mathrm{mmol}$ in $0.1 \%$ mercaptoethanol, without Trycine) were combined (unless otherwise noted), dried down using a Savant Speed Vac Concentrator, and resuspended in $1 \mu \mathrm{l}$ PBS, pH 7.2. Rats were anesthetized $(2.5 \mathrm{ml} / \mathrm{kg}$ body weight with Chloropent and placed into a Kopf stereotaxic apparatus. The coordinates used (top of skull horizontal) were: $2.5 \mathrm{~mm}$ caudal to bregma, $0.6 \mathrm{~mm}$ lateral (on both sides) to the midline, and $8.6 \mathrm{~mm}$ below dura. In some pairs, just before beginning of infusion, one rat was given an implant containing $E_{2}$ and one was given an empty implant, s.c. under the nape of the neck. A $1 \mu$ l syringe (Hamilton 7101 $\mathrm{N}$; flat-tipped needle 86200) was used to infuse the labeled amino acids into the VMH, $450 \mu \mathrm{Ci}$ in $0.5 \mu$ lover $50 \mathrm{~min}$ on each side. After infusion, holes in the skull were sealed with bone wax, wounds were closed by wound clips, and rats were injected i.p. $(600 \mu \mathrm{l} / \mathrm{kg}$ body weight) with $0.1 \%$ Metrazol (pentylenetetrazol; Sigma) to hasten arousal.

To study the contributions of transport versus diffusion of label to the MCG, $10 \mu \mathrm{g}$ colchicine in $1 \mu \mathrm{l}$ PBS or PBS alone was infused unilaterally into the lateral ventricle over a period of $2 \mathrm{~min}$ (Harlan et al., 1982) $24 \mathrm{hr}$ before radioactive label was infused into the VMH. Fourteen hours after radiolabel infusion, appropriate brain regions (see below) were microdissected, and the total TCA-precipitable counts were compured to determine the degree to which colchicine reduced radioactivity in the MCG. To visualize label in axons (presumably transported) versus cell bodies (presumably synthesized locally) in the MCG, $200 \mu \mathrm{Ci}{ }^{3} \mathrm{H}$-leucine in $1 \mu \mathrm{l} \mathrm{PBS}$, rather than ${ }^{35} \mathrm{~S}$-methionine and -cysteine, was infused in the VMH following the usual protocol. Rats were anesthetized with Chloropent either immediately after infusion or $12 \mathrm{hr}$ later and perfused transcardially with $10 \%$ formalin-saline. The brains remained in $10 \%$ formalin at least a week. The brains were processed for autoradiography according to Krieger et al. (1979) and developed 2 months after exposure to emulsion.

Dissection. Rats were sacrificed $12 \mathrm{hr}$ after the end of infusion with radioactive amino acids (either $14 \mathrm{hr}$ or 1 week after implantation of $\mathrm{E}_{2}$ ), and small brain regions were obtained using fresh brain microdissection procedures (Cuello and Carson, 1983). We preferred to dissect fresh brain because we could ensure that all regions of intcrest wcre frozen in less than $10 \mathrm{~min}$ after sacrifice; we could dissect most regions more accurately due to greater clarity of landmarks; and we could more directly compare the results from in vivo labeling with in vitro labeling of fresh punches. Briefly, rats were anesthetized with an overdose of Chloropent $\left(1 \mathrm{ml}\right.$ undiluted). They were brought into a cold room $\left(4^{\circ} \mathrm{C}\right)$ and perfused transcardially with $50 \mathrm{ml} \mathrm{PBS}$, also at $4^{\circ} \mathrm{C}$. After decapitation, the brains were quickly removed and placed on a McIlwain tissue chopper (Brinkman). Three tissue slabs were cut: first (POA) slab from $2.5 \mathrm{~mm}$ rostral to the optic chiasm to $0.5 \mathrm{~mm}$ caudal to the chiasm; second (MBH) slab from the caudal edge of the first slab to $4 \mathrm{~mm}$ caudal; and third (MCG) slab from the caudal edge of the second slab to $5 \mathrm{~mm}$ caudal. Usually, 2 bilateral sets of punches were taken from the POA slab (the POA and the region immediately lateral to it); 7 sets from the MBH slab (the median eminence, the VMH, regions immediatcly lateral, dorsolateral, dorsal, $3 \mathrm{~mm}$ dorsolateral, and the amygdala); and 3 sets from the MCG slab (the MCG, a cortical area, and a region $2 \mathrm{~mm}$ lateral to the MCG). The brain areas of interest were visible in these slabs by viewing over a fluorescent Glow-Box (IIR) and were removed using a Pasteur pipette ( $1 \mathrm{~mm}$ i.d.), placed directly into $50 \mu$ lysis buffer (see below), and frozen immediately in a dry ice/ethanol bath. In some early studies, rats were killed by decapitation and medial basal hypothalamus and MCG samples were dissected out crudely by hand; effects of $E_{2}$ were not influenced by method of sacrifice or dissection. The pituitary and small samples of blood and liver were also taken and treated in the same manner. Incorporation of radiolabel (usually ${ }^{35} \mathrm{~S}$ methionine and -cysteine) into protein was determined by precipitating in 10\% trichloroacetic acid (TCA), eliminating nonspecific binding by mercaptoethanol and iodoacetic acid as suggested by $\mathrm{New}$ England $\mathrm{Nu}$ clear, collecting the precipitate by a Whatmann GFA filter, and counting the whole filter in scintillation fluid. In general, $5 \times 10^{5} \mathrm{cpm}$ of TCAprecipitable radioactivity from each VMH sample, and $5 \times 10^{4}$ TCAprecipitable cpm from each MCG punch, were subjected to electrophoresis, in matched pairs. In most cases, duplicate aliquots from each sample were analyzed.

Protein separations on 2-dimensional gel electrophoresis. Sample proteins were separated on 2-dimensional PAGE, based on the procedure of O'Farrell (1975). Samples were placed into lysis buffer containing $9 \mathrm{M}$ urea (Ultra-pure, Schwartz-Mann), 2\% NP-40 (Shell), and 2\% Ampholines (1.6\% pH 3-7, 0.4\% pH 3.5-10; LKB Instruments). Separation in the first dimension, in which proteins separated based on isoelectric point, was carried out in $1.5 \mathrm{~mm}$ (i.d.) glass tubes containing $9 \mathrm{M}$ urea $2 \%$ Ampholines (1.6\% pH 3-7, 0.4\% pH 3.5-10; LKB), and 2\% NP-40 in a $3 \%$ polyacrylamide gel. Acrylamide was from Sigma; bis-acrylamide, TEMED, and $\beta$-mercaptoethanol were from BioRad; water was distilled then deionized (Barnstead). The second dimension of separation was a discontinuous SDS gel (O'Farrell, 1975), with a stacking gel of $4 \%$ acrylamide, $\mathrm{pH} 8.8$, and a lower resolving gel of $12.5 \%$ acrylamide, pH 6.8. The tube gels $(11 \mathrm{~cm}$ long) were placed into a trough made in the stacking gcl, scaled with a $1 \%$ agarose (Sigma) solution, and subjected to a current of $25 \mathrm{~mA} / \mathrm{gel}$ in a BioRad (Hoefer) gel tank. Isoelectric points were determined by measuring $\mathrm{pH}$ of tube gels using an LKB surface $\mathrm{pH}$ electrode. Isoelectric points of actin, tubulin, and albumin measured in this way agreed with published values. Molecular weight markers were run in a lane next to the tube gels. The current was maintained until 30 min after the bromphenol blue dye front had run off the gels. After the second dimension was run, gels were fixed and stained simultaneously in $10 \%$ TCA, $12.5 \% \mathrm{MeOH}, 5 \%$ acetic acid, and $0.1 \%$ Coommassie blue R-250 (Sigma). Gels were destained in 12.5\% $\mathrm{MeOH}, 5 \%$ acetic acid, then processed with EnHance (New England Nuclear) for fluorography using Kodak XAR-5 film at $-70^{\circ} \mathrm{C}$. VMH samples were exposed for 2 weeks, and MCG samples were exposed for about 12 weeks. For graphical representation and subsequent quantitation, some spots were scanned using a Biomed soft laser scanning densitometer (SL-2D) and supplied software (Videophoresis I) on an Apple IIe computer.

\section{Results}

\section{Radioactivity primarily in $V M H$ and projections from $V M H$}

The VMH consistently had the highest radioactivity of any region; radioactivity declined sharply further than $1 \mathrm{~mm}$ away from the VMH. The POA had about 10 times higher radioactivity than the region immediately lateral. Similarly, the MCG samples had about 10 times higher radioactivity than samples $1 \mathrm{~mm}$ dorsolateral (Table 1 ). These results suggested that as much as $90 \%$ of the label in the POA and MCG might be due to transport rather than diffusion, since these regions have been shown to contain heavy axonal projections from the VMH (Krieger et al., 1979). To address further the contribution of transport versus diffusion, a separate study examined the effect of colchicine on the distribution of label. Infusion of $10 \mu \mathrm{g}$ colchicine into the lateral ventricle $24 \mathrm{hr}$ before infusing radioactive label decreased the TCA-precipitable radioactivity in the MCG by about $90 \%$ (Table 2; $p<0.05, t$ test).

These results were corroborated in a separate study in which $200 \mu \mathrm{Ci}{ }^{3} \mathrm{H}$-leucine in $1 \mu \mathrm{l}$ was infused into the $\mathrm{VMH}$ following the protocol used for infusing ${ }^{35} \mathrm{~S}$-methionine. Either immediately after the end of infusion or 12 hrs later, rats were killed, the brains were fixed or processed for autoradiography (Krieger et al., 1979), and the distribution of reduced silver grains was examined microscopically. In brains obtained immediately after infusion, the grains were largely confined to within $0.5 \mathrm{~mm}$ of the dorsal aspect of the ventromedial nucleus. In brains obtained 12 hrs after the end of infusion, many more grains were visible over the POA and MCG than over immediately lateral areas. In both the POA and MCG, most grains appeared to follow axonal projections similar to those previously described connecting these regions to the VMH (Krieger et al., 1979). Some cell bodies in the ventricular ependyma surrounded by the MCG did appear to be labeled, although few cell bodies further than $100 \mu \mathrm{m}$ from the ependyma appeared to bc labcled. Thus, some label appeared to leak from the VMH into the third 
no $E_{2}$

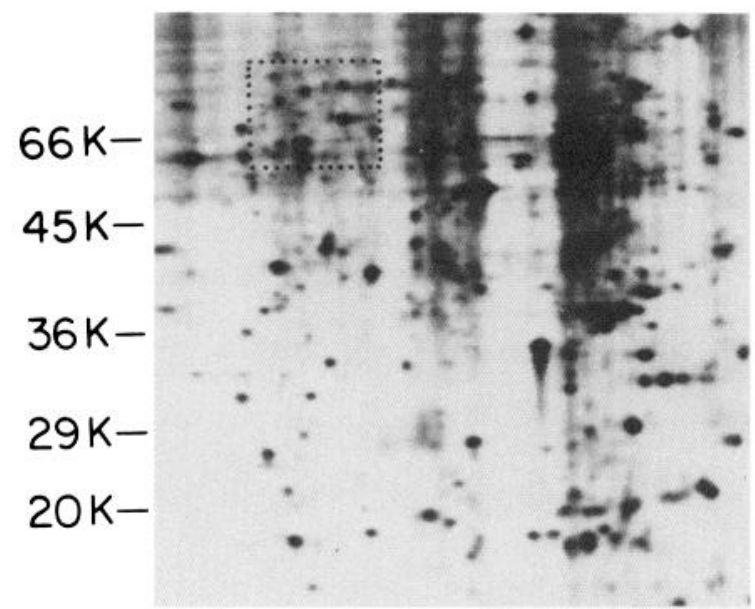

$E_{2}$

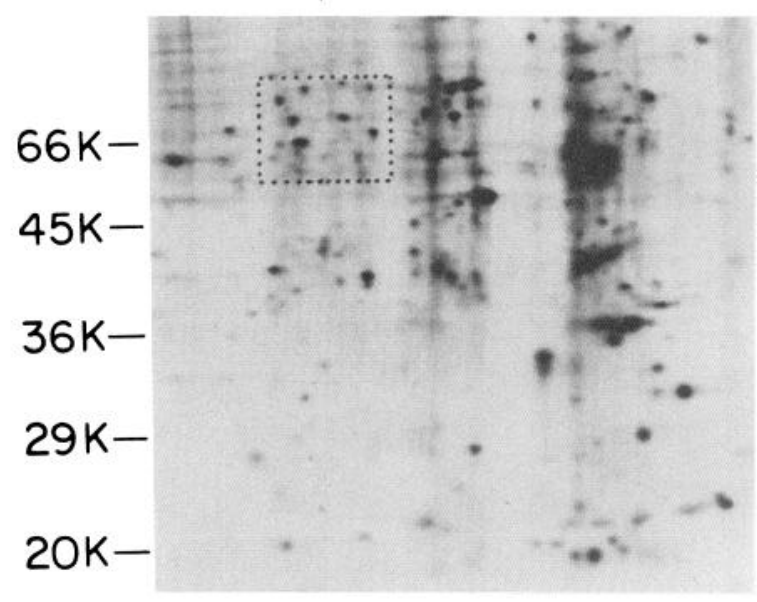

Figure 1. Representative 2-dimensional gel patterns from the ventromedial hypothalamus of individual ovariectomized rats, either given no $\mathrm{E}_{2}$ replacement (no $\mathrm{E}_{2}$ ) or given $\mathrm{E}_{2}$-containing capsules $\left(\mathrm{E}_{2}\right) 14 \mathrm{hr}$ before sacrifice. ${ }^{35} \mathrm{~S}$-methionine $(600 \mu \mathrm{Ci})$ and ${ }^{35} \mathrm{~S}$-cysteine $(300 \mu \mathrm{Ci})$ were infused into the VMH $14 \mathrm{hr}$ before sacrifice and microdissection. The VMH was microdissected and 500,000 TCA-precipitable cpm were subjected to separation by 2-dimensional gel electrophoresis (O'Farrell, 1975), prepared for fluorography, and exposed to X-ray film at $-70^{\circ} \mathrm{C}$ for 1 week. The boxed areas are representative of the areas displayed in more detail in Figure 3. Basic proteins to the left.

ventricle, and some of this label diffused to the ependyma near the MCG.

\section{Two-dimensional gel analysis: $E_{2}$-induced $70 \mathrm{kDa}$ protein in $V M H$ and $M C G$}

When $5 \times 10^{5} \mathrm{cpm}$ of TCA-precipitable counts from VMH samples were subjected to 2-dimensional gel electrophoresis,

\section{no $E_{2}$}

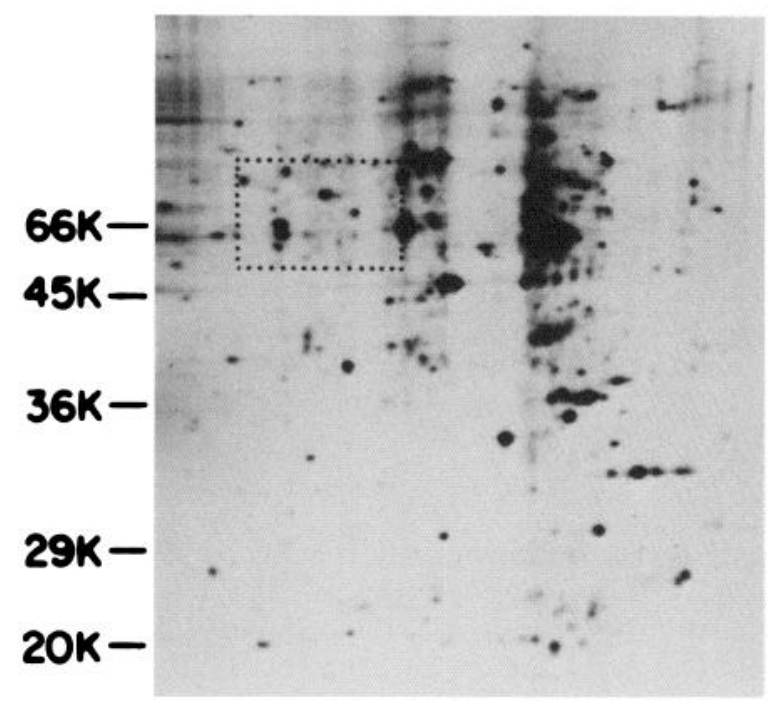

processed, and exposed for 2 weeks, more than 250 spots could be reliably identified based on position (Fig. 1). When $5 \times 10^{4}$ cpm of TCA-precipitable counts from MCG were subjected to the same procedure, but exposed for 12 weeks, more than 75 spots were uniquely identified (Fig. 2). The spots ranged in apparent molecular weight (based on molecular weight standards run with every gel) from about $14 \mathrm{kDa}$ to about $100 \mathrm{kDa}$; they ranged in apparent $\mathrm{pI}$ (based on $\mathrm{pH}$ measurements and

\section{$E_{2}$}

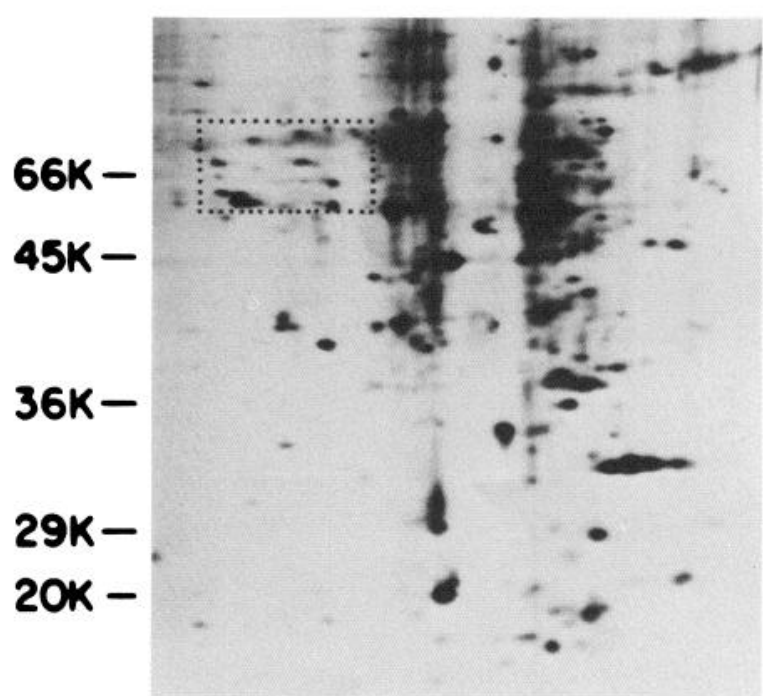

Figure 2. Representative 2-dimensional gel patterns from the midbrain central gray area of individual ovariectomized rats, either given no $\mathrm{E}_{2}$ replacement (no $\mathrm{E}_{2}$ ) or given $\mathrm{E}_{2}$-containing implants $14 \mathrm{hr}$ before sacrifice. ${ }^{35} \mathrm{~S}$-methionine $(600 \mu \mathrm{Ci})$ and ${ }^{35} \mathrm{~S}$-cysteine $(300 \mu \mathrm{Ci})$ were infused into the VMH $14 \mathrm{hr}$ before sacrifice and microdissection. The MCG was dissected and 50,000 TCA-precipitable cpm were subjected to separation by 2-dimensional gel electrophoresis (O'Farrell, 1975), prepared for autoradiography, and exposed to X-ray film at $-70^{\circ} \mathrm{C}$ for 10 weeks. The boxed areas are representative of the areas displayed in more detail in Figure 3. 

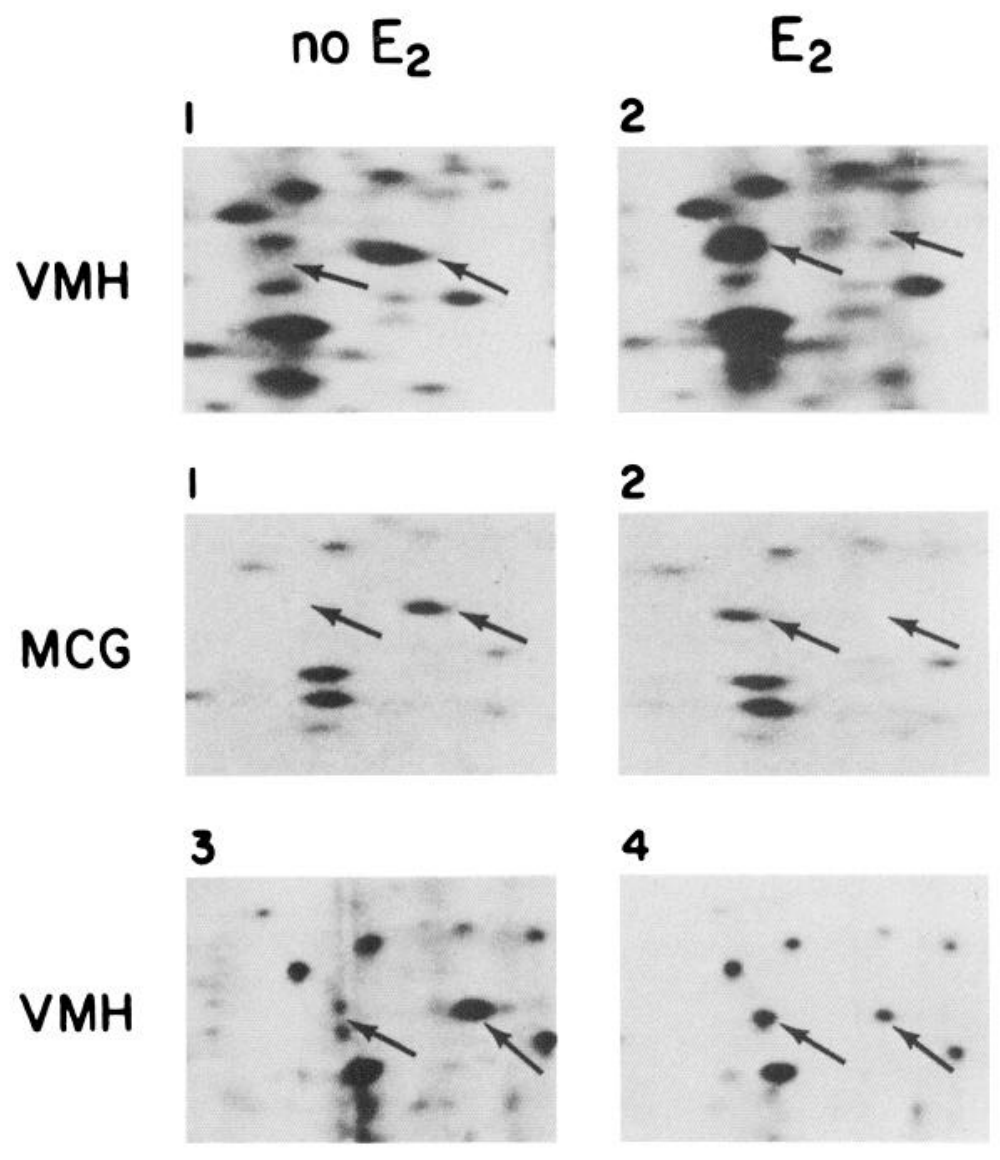

Figure 3. $\mathrm{E}_{2}$-regulated protein spots from the VMH and MCG of individual rats. Rats were treated and tissue was prepared and analyzed as described in Figures 1 and 2. The area shown corresponds roughly to the boxed areas in Figures 1 and 2 . The number in the upper left of each box indicates the individual animal number. Left arrow indicates spot increased by $\mathrm{E}_{2}$, right arrow indicates spot decreased by $\mathrm{E}_{2}$.

\section{3}

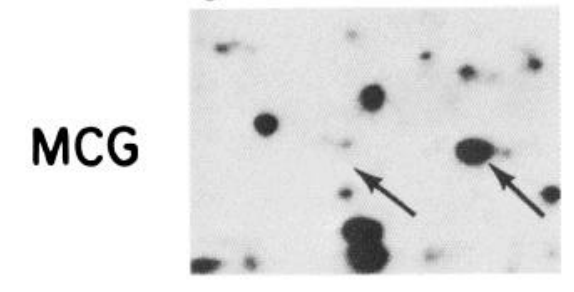

4

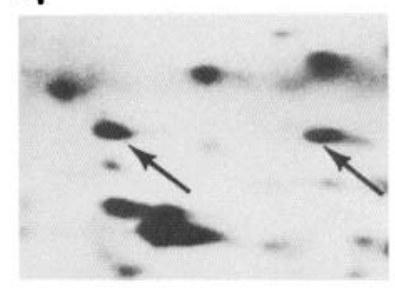

comparison with gel patterns in the literature) from about $\mathrm{pH}$ 4.5 to about 6.5 .

The spot patterns were very similar, but not identical, in gels from samples labeled under different conditions. Samples from the whole crudely dissected MBH had more spots than did VMH samples, although almost all spots found in VMH samples could be identified in MBH samples. Spot patterns from samples labeled with methionine only or cysteine only differed qualitatively in only about 10 spots out of 250 . Thus, the later studies pooled these 2 isotopes for labeling.

Although several spots may have been influenced by $E_{2}$, one spot was consistently and qualitatively increased in rats treated with $\mathrm{E}_{2}$ (Fig. 3) compared with ovariectomized rats. Computergenerated depiction of this spot shows that the spot is virtually undetectable in ovariectomized rats but is a major spot in $\mathrm{E}_{2}$ treated rats (Fig. 4, spot b). Because of background and nonlinearity problems in the vicinity of the $70 \mathrm{kDa}$ spot, we did not feel that quantitation of this particular spot was either helpful or valid. However, spots on some pairs of gels occasionally seemed to be influenced by $\mathrm{E}_{2}$; quantitation of these gels may later reveal more subtle and less consistent quantitative effects of $E_{2}$. The spot that is the focus of this report had an apparent molecular weight of about $70 \mathrm{kDa}$, and an apparent $\mathrm{pI}$ of about 5.9. In the first 8 pairs of rats in this study, and in 5 of the next 8 pairs, this $70 \mathrm{kDa}$ spot was present in the $\mathrm{E}_{2}$-treated rats but not in the ovariectomized rats. This spot was visible in samples from $8 / 10$ rats exposed to $E_{2}$ for 14 hours, and $5 / 6$ rats exposed to $E_{2}$ for 1 week, compared with $2 / 16$ sham-implanted rats $(p<$ $\left.0.05, \chi^{2}\right)$.

Another spot, immediately to the acidic side of the induced spot (same molecular weight, pI 5.8) tended to be decreased in $\mathrm{E}_{2}$-treated rats compared with ovariectomized rats not given $\mathrm{E}_{2}$ (Fig. 3). This spot was present in $16 / 16$ ovariectomized rats but only in $12 / 16 \mathrm{E}_{2}$-treated rats, and in those 12 , this spot appeared to be less dense in the $E_{2}$-treated rat than in the paired ovariectomized control.

The $70 \mathrm{kDa}, 5.9 \mathrm{pI}$ spot was also increased by $\mathrm{E}_{2}$ in the MCG samples (Fig. 3). The relative contributions of the $5.9 \mathrm{pI}$ spot and the $5.8 \mathrm{pI}$ spot appeared to be very similar in the $\mathrm{VMH}$ and MCG of a given individual rat. 

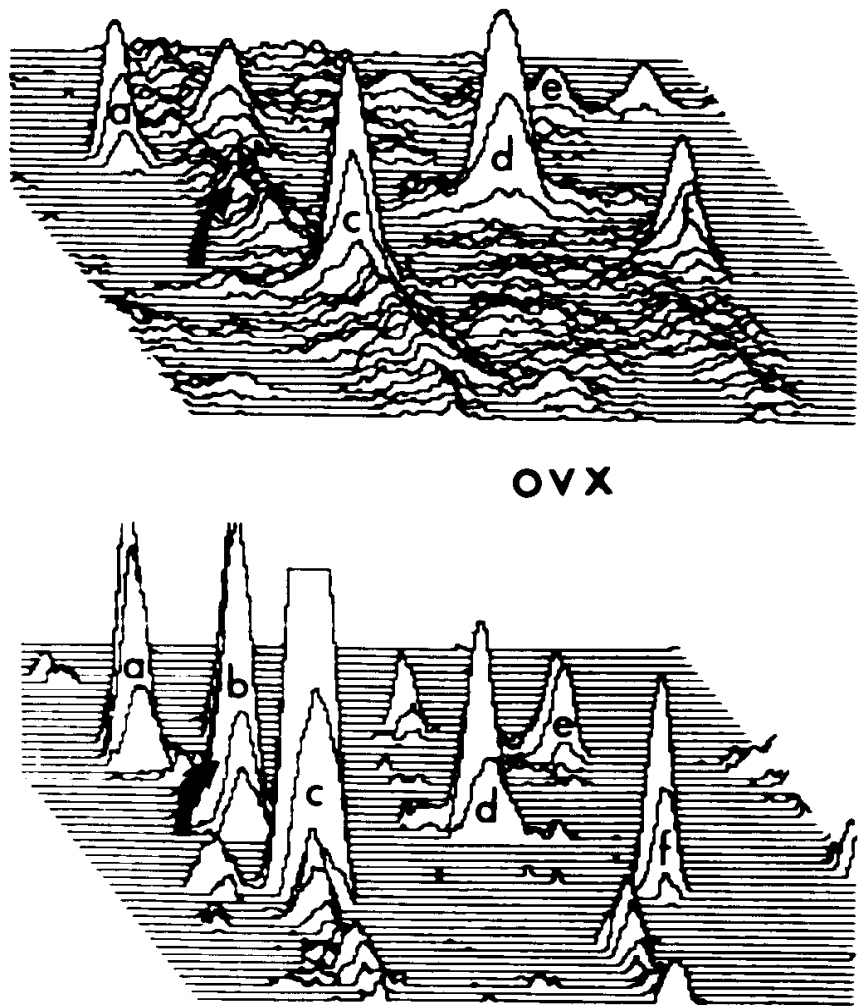

E

Figure 4. Graphical representation of computerized densitometric analysis of one $E_{2}$-regulated protein spot. Rats were treated and tissue was prepared and subjected to 2-dimensional gel analysis as described in Figures 1 and 2. Autoradiograms were quantitated using the Biomed 2-D flatbed laser densitometer and associated software on an Apple IIe microcomputer. Height on the graph corresponds to the density of each pixel. Left arrow indicates spot increased by $\mathrm{E}_{2}$, right arrow indicates spot decreased by $E_{2}$.

\section{Discussion}

These data suggest that a specific protein, apparent molecular weight of $70 \mathrm{kDa}$ and $\mathrm{pI} 5.9$, is induced by $\mathrm{E}_{2}$ in the $\mathrm{VMH}$, and that this protein is transported to the MCG. The spot was clearly present in samples from $13 / 16 \mathrm{E}_{2}$-treated rats and present in samples from only $2 / 16$ ovariectomized rats $\left(p<0.01, \chi^{2}\right)$. The induction was apparent $14 \mathrm{hr}$ after exposure to $E_{2}$ and continued as long as a week during exposure to $E_{2}$. In view of the lack of absolute correlation with $\mathrm{E}_{2}$ exposure, it is conceivable, though unlikely, that the pair of $70 \mathrm{kDa}$ spots represents a genetic polymorphism, rather than a response to $E_{2}$.

Three lines of evidence suggest that the appearance of the $E_{2}$ induced $70 \mathrm{kDa}$ spot in the MCG is due at least in part to transport of the induced protein from the VMH to the MCG, rather than entirely from local synthesis. First, analysis of the diffusion of radioactive label away from the infusion site suggests that the majority of label in the MCG did not arrive by diffusion. Analysis of TCA-precipitable radioactivity in micropunches near the VMH show that, except in regions with projections from the $\mathrm{VMH}, 80-90 \%$ of the label is found within 1 $\mathrm{mm}$ of the VMH. Thus, by diffusion alone, the MCG, which is about $7 \mathrm{~mm}$ away from the point of infusion, would be expected to contain less than $0.01 \%$ of the counts in the VMH. Also, the MCG and preoptic area had about 10- to 20-fold higher amounts of radioactivity than nearby regions with fewer axonal projec-
Table 1. TCA-precipitable radioactive cpm in preoptic area (POA), ventral medial hypothalamus (VMH), and midbrain central gray (MCG) after infusion of ${ }^{35}$ S-methionine and -cysteine into the VMH

\begin{tabular}{llcc} 
Area & VMH & POA & MCG \\
\hline At site & $93,829 \pm 12,139$ & $25,501 \pm 4689$ & $5012 \pm 938$ \\
1 mm from sitc & $16,108 \pm 2431$ & $2173 \pm 334$ & $312 \pm 55$
\end{tabular}

Microdissected punches were taken at these areas or $1 \mathrm{~mm}$ away from these areas in regions with relatively few projections from the VMH. See text for further details on microdissection. Each value represents punches from 16 rats. Samples taken $1 \mathrm{~mm}$ away from site have about the same amount of tissue as the site itself; however, VMH, POA, and MCG punches have different amounts of tissue, so values cannot be directly compared between sites. The number represents $10 \%$ of the total radioactivity in each tissue.

tions from the VMH (Table 1). Autoradiographic analysis of brains given tritiated leucine with the same protocol as used for these studies showed that grains accumulated primarily over cell bodies in the VMH but primarily over axonal projections in the MCG; the only substantial grains over cell bodies in the MCG were in the ependyma surrounding the cerebral aqueduct, which are not cells that concentrate $E_{2}$ to a significant extent (Pfaff and Keiner, 1973). Second, colchicine, which blocks axonal transport, also significantly reduced radioactivity in the MCG (Table 2). Third, the microheterogeneity of the two 70 $\mathrm{kDa}$ spots-i.e., the relative densities of proteins $5.9 \mathrm{pI}$ versus $5.8 \mathrm{pI}-$ was similar in the VMH and MCG within a given rat, although this portion varied among rats. It seems unlikely that the relative levels of these 2 proteins would match so precisely if they were independently induced.

It is unclear whether $E_{2}$ induces the synthesis of this protein or whether the appearance of this spot in the presence of $E_{2}$ is due to the modification of another protein, in particular the 70 $\mathrm{kDa}, 5.8 \mathrm{pI}$ protein immediately to its acidic side. The apparent inverse relationship between the densities of these 2 proteins, including the striking result that when the $5.9 \mathrm{pI}$ protein is maximally induced the $5.8 \mathrm{pI}$ protein is completely invisible, suggests strongly that $E_{2}$ is causing a modification, rather than an induction. The direction of the modification would suggest a reduction in the number of negative charges, e.g., a dephosphorylation in the presence of $E_{2}$. These 2 spots appear to have the same molecular weights and are very well-defined, which suggests that $E_{2}$ could not be causing a large change in glycosylation.

The characterization of the estrogen-induced protein reported here is novel in several respects, in addition to the in vivo labeling strategy, although effects of gonadal steroids on protein synthesis have been noted before. Using 2-dimensional gel electrophoresis followed by silver-staining, Scouten et al. (1985) have reported that the levels of 11 out of 119 proteins are quantitatively different in intact estrous females and ovariectomized females. In

\section{Table 2. Effect of colchicine in lateral ventricle on the ratio of radioactivity in midbrain central gray (MCG) versus ventromedial hypothalamus (VMH)}

$\% \mathrm{MCG} / \mathrm{VMH}$

Saline $(n=4)$

$9.7 \pm 3.5$

Colchicine $(n=4)$

$1.2+0.5$

Ratio was determined by dividing TCA-precipitable radioactive cpm in midbrain central gray (MCG) by TCA-precipitable cpm in the VMH and expressing as percentage. Either saline or $10 \mu \mathrm{g}$ colchicine was infused into the lateral ventricle $24 \mathrm{hr}$ before infusion of label into VMH. 
an abstract, Jones et al. (1985) reported a study using 2-dimensional gel electrophoresis to separate proteins from VMH tissue incubated in vitro with ${ }^{35} \mathrm{~S}$-methionine and -cysteine; they also reported quantitative effects of $E_{2}$ on several proteins, although the properties and degree of induction of specific proteins were not given. However, neither of these studies reported an estrogen-induced protein with the properties of the protein reported here, and no estrogen-induced protein has been shown to be transported. A preliminary note (Pfaff et al.; 1984) was consistent with such a result, but the protein was not characterized nor was transport clearly established. Furthermore, the protein is synthesized in and transported to regions that suggest it may be functionally relevant to female sexual behavior. No other reported brain protein has shown such a large induction by estrogen. In these studies the protein was not detectable in the absence of estrogen, thus was induced by more than 10 -fold. The degree of induction is a relevant issue since $E_{2}$ has profound effects on protein synthetic machinery in neurons of the VMN, suggesting that it must cause very large changes in the synthesis of some proteins, and $E_{2}$ has profound morphological and behavioral effects, which seem unlikely to result from very small synthetic changes. The existence of such a protein, which is qualitatively induced by estrogen in the VMN and transported to the MCG, supports the hypothesis that estrogen modulates lordosis by inducing the synthesis of specific proteins, which are then transported to the MCG.

The $\mathrm{E}_{2}$-induced $70 \mathrm{kDa}, 5.9 \mathrm{pI}$ protein is extremely similar in molecular weight, isoelectric point, and abundance to one of the bovine brain isoproteins that removes clathrin from coated vesicles (Ungewickell, 1985). Clathrin must be removed from coated (secretory) vesicles before fusion of the vesicle with membrane can occur (Rothman and Schmid, 1986), since it prevents fusion of the membrane bilayers (Altstiel and Brandon, 1983). The isoforms of this protein, all of which have molecular weights of about $70 \mathrm{kDa}$, have pIs of 5.5, 5.6, 5.8, and 5.9; the major isoform, $\mathrm{pI} 5.6$, constitutes about $0.1 \%$ of the total protein from bovine brain and the minor isoforms normally constitute much smaller amounts (Ungewickell, 1985). These uncoating isoproteins are, in turn, extremely similar-in antibody cross-reactivity, clathrin binding, molecular weight, isoelectric points, and peptide mapping-to the $70 \mathrm{kDa}$ stress-induced (heat-shock) proteins (Ungewickell, 1985; Chappell et al., 1986). These stress proteins are synthesized in neurons (Greenberg and Lasek, 1985) and axonally transported (Clark and Brown, 1985). The stress proteins are also similar-by peptide mapping, molecular weight, and $\mathrm{pI}-$ to another set of brain isoproteins, the microtubule associated proteins (MAPs) (Whatley et al., 1986). The $70 \mathrm{kDa}$ (relatively basic) isoform of MAP whose $\mathrm{pI}$ seems most similar to the $\mathrm{E}_{2}$-induced protein reported here is associated specifically with brain synaptic vesicles (Whatley et al., 1986). Since this (relatively basic) synaptic isoform of MAP is, by peptide mapping, very similar to the stress proteins, all of which have clathrin binding activity in the presence of ATP (Ungewickell, 1985), this isoform of MAP may be the $5.9 \mathrm{pI}$ minor isoform of uncoating protein. Therefore, the synaptic isoform of MAP may be associated with removing clathrin from synaptic vesicles to facilitate synaptic transmission. Since preliminary evidence also suggests that the $\mathrm{E}_{2}$-induced $70 \mathrm{kDa}, 5.9 \mathrm{pI}$ protein is associated with synaptic vesicles, we are currently examining the possible identity of this protein as the synaptic isoform of MAP and/or the $5.9 \mathrm{pI}$ isoform of the $70 \mathrm{kDa}$ uncoating protein. The inducibility by $E_{2}$ of an isoform of the $70 \mathrm{kDa}$ stress protein family is plausible since at least some stress (heat-shock) proteins are induced by estradiol (Baez et al., 1987) and the steroid ecdysterone (Vitek and Berger, 1984). If the $\mathrm{E}_{2}$-induced protein is a synaptic uncoating protein, which is by no means established, this would suggest that one mechanism by which $E_{2}$ regulates neuronal function involves facilitating fusion of synaptic vesicles.

\section{References}

Alstiel, L., and D. Brandon (1983) Fusion of coated vesicles with lysosomes: Measurement with a fluorescence assay. Cell 32: 921-929.

Baez, M., D. R. Sargan, A. Elbrecht, M. S. Kulomaa, T. Zarucki-Schulz, M.-J. Tsai, and B. W. O'Malley (1987) Steroid hormone regulation of the gene encoding the chicken heat shock protein hsp 108. J. Biol. Chem. 262: 6582-6588.

Chappell, T. G., W. J. Welch, D. M. Schlussman, K. B. Palter, M. J. Schlesinger, and J. E. Rothman (1986) Uncoating ATPase is a member of the 70 kilodalton family of stress proteins. Cell 45: 3-13.

Clark, B. D., and I. K. Brown (1985) Axonal transport of a heat shock protein in the rabbit visual system. Proc. Natl. Acad. Sci. USA 82 : 1281-1285.

Cuello, A. C., and S. Carson (1983) Microdissection of fresh rat brain tissue slices. In Brain Microdissection Techniques, A. C. Cuello, ed., pp. 37-126, Wiley, New York.

Greenberg, S. G., and R. J. Lasek (1985) Comparison of labeled heat shock proteins in neuronal and non-neuronal cells of Aplysia californica. J. Neurosci. 5: 1239-1245.

Harlan, R. E., B. D. Shivers, L.-M. Kow, and D. W. Pfaff (1982) Intrahypothalamic colchicine infusions disrupt lordotic responsiveness in estrogen-treated female rats. Brain Res. 238: 153-167.

Jones, K. J., B. S. McEwen, and D. W. Pfaff (1985) Effects of estradiol $\left(E_{2}\right)$ on protein synthesis in vitro, in the ventromedial hypothalamic nucleus (VMN) and preoptic area (POA) of the female rat. Soc. Neurosci. Abst. 11: 736(\#216.10).

Krieger, M. S., L. C. A. Conrad, and D. W. Pfaff (1979) An autoradiographic study of the efferent connections of the ventromedial nucleus of the hypothalamus. J. Comp. Neurology 183: 785-816.

Meisel, R. L., and D. W. Pfaff (1985) Specificity and neural sites of action of anisomycin in the reduction or facilitation of female sexual behavior in rats. Hormones Behavior 19: 237-251.

O'Farrell, P. H. (1975) High resolution two-dimensional gel electrophoresis of proteins. J. Biol. Chem. 250: 4007-4021.

O'Malley, B. W., and A. R. Means (1974) Female steroid hormones and target cell nuclei. Science 183: 610-620.

Pfaff, D. W. (1980) Estrogens and Brain Function, Springer, New York.

Pfaff, D., and M. Keiner (1973) Atlas of estradiol-concentrating cells in the central nervous system of the female rat. J. Comp. Neurol. 151 : 121-158.

Pfaff, D. W., L. Rosello, and P. Blackburn (1984) Proteins synthesized in medial hypothalamus and transported to midbrain in estrogentreated female rats. Exp. Brain Res. 57: 204-207.

Rothman, J. E., and S. L. Schmid (1986) Enzymatic recycling of clathrin from coated vescicles. Cell 46: 5-9.

Sakuma, Y., and D. W. Pfaff (1979) Mesencephalic mechanisms for integration of female reproductive behavior in the rat. Am. J. Physiol. 237: R285-R290.

Scouten, C. W., W. E. Heydorn, J. G. Creed, C. W. Malsbury, and D. M. Jacobowitz (1985) Proteins regulated by gonadal steroids in the medial preoptic and ventromedial hypothalamic nuclei of male and female rats. Neuroendocrinology 41: 237-245.

Ungewickell, E. (1985) The 70-kd mammalian heat shock proteins are structurally and functionally related to the uncoating protein that releases clathrin triskelia from coated vesicles. EMBO J. 4: 33853391.

Vitek, M. P., and E. M. Berger (1984) Steroid and high-temperature induction of the small heat-shock protein genes in Drosophila. J. Mol. Biol. 178: 173-189.

Whatley, S. A., T. Leung, C. Hall, and L. Lim (1986) The brain 68kilodalton microtubule-associated protein is a cognate form of the 70-kilodalton mammalian heat-shock protein and is present as a specific isoform in synaptosomal membranes. J. Neurochem. 47: 15761583. 